\title{
Convergent Evolution of Sodium Ion Selectivity in Metazoan Neuronal Signaling
}

\author{
Maya Gur Barzilai, ${ }^{1}$ Adam M. Reitzel, ${ }^{2}$ Johanna E.M. Kraus, ${ }^{3}$ Dalia Gordon, ${ }^{1}$ Ulrich Technau, ${ }^{3}$ Michael Gurevitz, ${ }^{1}$ \\ and Yehu Moran ${ }^{3, *}$ \\ ${ }^{1}$ Department of Molecular Biology and Ecology of Plants, George S. Wise Faculty of Life Sciences, Tel-Aviv University, Tel-Aviv 69978, Israel \\ 2Biology Department, Woods Hole Oceanographic Institution, Woods Hole, MA 02543, USA \\ 3Department of Molecular Evolution and Development, Faculty of Life Sciences, University of Vienna, Althanstraße 14, 1090 Vienna, Austria \\ *Correspondence: yehu.moran@univie.ac.at \\ http://dx.doi.org/10.1016/j.celrep.2012.06.016
}

\section{SUMMARY}

lon selectivity of metazoan voltage-gated $\mathrm{Na}^{+}$channels is critical for neuronal signaling and has long been attributed to a ring of four conserved amino acids that constitute the ion selectivity filter (SF) at the channel pore. Yet, in addition to channels with a preference for $\mathrm{Ca}^{2+}$ ions, the expression and characterization of $\mathrm{Na}^{+}$channel homologs from the sea anemone Nematostella vectensis, a member of the early-branching metazoan phylum Cnidaria, revealed a sodium-selective channel bearing a noncanonical SF. Mutagenesis and physiological assays suggest that pore elements additional to the SF determine the preference for $\mathrm{Na}^{+}$in this channel. Phylogenetic analysis assigns the Nematostella $\mathrm{Na}^{+}$-selective channel to a channel group unique to Cnidaria, which diverged $>540$ million years ago from $\mathrm{Ca}^{2+}$-conducting $\mathrm{Na}^{+}$channel homologs. The identification of Cnidarian $\mathrm{Na}^{+}$-selective ion channels distinct from the channels of bilaterian animals indicates that selectivity for $\mathrm{Na}^{+}$in neuronal signaling emerged independently in these two animal lineages.

\section{INTRODUCTION}

The emergence of nervous systems that enable the integration of external stimuli and coordinated responses was a key event in the evolution of animal body plans. Signaling in these systems is based on fast and accurate propagation and conductance of action potentials involving voltage-gated sodium channels $\left(\mathrm{Na}_{\mathrm{v}} \mathrm{s}\right)$ (Hille, 2001; Meech and Mackie, 2007). $\mathrm{Na}_{\mathrm{v}} \mathrm{s}$ are membrane-spanning protein complexes that are composed of pore-forming $\alpha$-subunits and auxiliary subunits, and conduct $\mathrm{Na}^{+}$ions in response to changes in the membrane potential (Catterall, 2000; Hille, 2001). The $\alpha$-subunit, which belongs to a protein superfamily of voltage-gated $\mathrm{Na}^{+}, \mathrm{K}^{+}$, and $\mathrm{Ca}^{2+}$ channels $\left(\mathrm{Na}_{\mathrm{v}} \mathrm{s}, \mathrm{K}_{\mathrm{v}} \mathrm{s}\right.$, and $\mathrm{Ca}_{\mathrm{v}} \mathrm{s}$, respectively), consists of four domains (DI-DIV) arranged around a central ion-conducting pore. Each domain is comprised of six transmembrane segments (S1-S6), of which the positively charged $S 4$ (voltage sensor) moves outward in response to membrane depolarization, leading to opening of the channel pore and ion conductance. Whereas the $\alpha$-subunit of $\mathrm{K}_{\mathrm{v}} \mathrm{s}$ is a single domain tetramer, the $\alpha$-subunits of $\mathrm{Ca}_{\mathrm{v}} \mathrm{s}$ and $\mathrm{Na}_{\mathrm{v}} \mathrm{s}$ are large monomers of four homologous, nonidentical domains (Hille, 2001).

Ion selectivity is crucial for fast and accurate signaling, and the emergence of $\mathrm{Na}^{+}$-selectivity likely addressed a need to distinguish neuronal stimuli from intracellular signaling driven by $\mathrm{Ca}^{2+}$ (Hille, 2001; Meech and Mackie, 2007). The selectivity of $\mathrm{Na}_{\mathrm{v}} \mathrm{s}$ for $\mathrm{Na}^{+}$ions is attributed to the ion selectivity filter (SF), a ring of four amino acids (Asp, Glu, Lys, and Ala [DEKA]) that are contributed by the pore-lining loops ( $p$-loop) of the four domains (Catterall, 2000). The Lys at the third position of the DEKA SF is critical for ion selectivity, as indicated by the increase in $\mathrm{Ca}^{2+}$ and $\mathrm{K}^{+}$conductance when it is substituted in mammalian $\mathrm{Na}_{\mathrm{v}} \mathrm{s}$ (Heinemann et al., 1992; Schlief et al., 1996). Although the DEKA SF is conserved in all vertebrate and many invertebrate $\mathrm{Na}_{v}$ s (Widmark et al., 2011), novel $\mathrm{Na}_{\mathrm{v}}$-like channels with a DEEA SF have been observed in many invertebrates, including arthropods, mollusks and tunicates (Zhou et al., 2004; Cui et al., 2012; Sato and Matsumoto, 1992; Nagahora et al., 2000). Still, only two of these $\mathrm{Na}_{\mathrm{v}}$-like channels, BSC1 of the cockroach Blattella germanica and DSC1 of Drosophila melanogaster, have been functionally expressed and shown to preferably conduct $\mathrm{Ca}^{2+}$ (Zhang et al., 2011; Zhou et al., 2004).

Understanding the evolutionary relationship between $\mathrm{Na}_{\mathrm{v}}$ and $\mathrm{Na}_{\mathrm{v}}$-like channels may shed light on the development of ion selectivity, and requires a broad data set for phylogenetic analysis. Previous analyses either focused on vertebrate channels or mostly used fragmented and nonverified gene models from invertebrates (Goldin, 2002; Widmark et al., 2011; Liebeskind et al., 2011). These analyses showed that $\mathrm{Na}_{\mathrm{v}}$-like channels existed in the common ancestor of animals and their unicellular relatives, choanoflagellates, and are present in the apusozoan Thecamonas trahens (Liebeskind et al., 2011; Cai, 2012). Because apusozoans diverged before the fungal-metazoan split occurred (Derelle and Lang, 2012), $\mathrm{Na}_{\mathrm{v}}$-like channels emerged before nervous systems or multicellularity evolved. Because $\mathrm{Na}_{\mathrm{v}}$-like channels from early branching phyla of animals or their protist relatives have not been studied directly, their impact on the evolutionary history of neuronal signaling has remained unclear.

To address this critical gap in knowledge, we focused on obtaining a phylogenetic and functional characterization of $\mathrm{Na}_{\mathrm{v}}$-like channels from the phylum Cnidaria (sea anemones, corals, 
hydroids, and jellyfish). This basal animal clade is a sister group to all higher animals (Bilateria) and was among the first lineages to develop a nervous system (Watanabe et al., 2009), and is therefore highly suitable for the study of $\mathrm{Na}_{\mathrm{v}}$ evolution in animals.

\section{RESULTS AND DISCUSSION}

Characterization of $\mathrm{Na}_{\mathbf{v}}$-like Homologs from $\mathbf{N}$. vectensis To study cnidarian $\mathrm{Na}_{\mathrm{v}}$-like channels, we used the starlet sea anemone Nematostella vectensis (Cnidaria, Anthozoa), whose genome has been fully sequenced (Putnam et al., 2007). A homology search of the genome retrieved five putative $\mathrm{Na}_{v}$ genes. cDNA cloning and sequencing revealed SFs resembling those found in $\mathrm{Na}_{\mathrm{v}}$-like channels. Channels with DEKA SF are termed $\mathrm{Na}_{v} 1$; therefore, we named the $\mathrm{Na}_{v}$-like channels $\mathrm{Na}_{v} 2$, and accordingly refer to the five Nematostella channels as $\mathrm{NvNa}_{\mathrm{v}} 2.1-2.5$. To functionally characterize these channels, we expressed them in Xenopus oocytes and examined their ion selectivity.

$\mathrm{NvNa}_{\mathrm{v}} 2.1$, bearing a DEEA SF, exhibited slowly developing activating and inactivating currents in response to depolarizing voltage pulses, and substantial tail currents when returned to a holding potential (Figure 1A). Such currents with a reversal potential $\left(E_{\text {rev }}\right)$ of $-13 \pm 1.2 \mathrm{mV}(n=8$; Figure $S 1 A)$ are reminiscent of $\mathrm{Cl}^{-}$ion conductance through $\mathrm{Ca}^{2+}$-activated $\mathrm{Cl}^{-}$channels endogenous to Xenopus oocytes (Barish, 1983). Because these currents were reduced by the $\mathrm{Na}_{v} 1$ blocker lidocaine, the $\mathrm{Cl}^{-}$currents were apparently triggered by $\mathrm{Ca}^{2+}$ influx through $\mathrm{NvNa}_{v} 2.1$ (Figure S1B). We removed the $\mathrm{Cl}^{-}$currents by injecting the $\mathrm{Ca}^{2+}$ chelator BAPTA into the oocytes, which uncovered voltage-dependent inward currents characterized by fast activation and slow inactivation kinetics, and $E_{\text {rev }}=21.6 \pm 2.2 \mathrm{mV}$ ( $n=7$; Figure S1C). Further, we eliminated the $\mathrm{Ca}^{2+}$-induced $\mathrm{Cl}^{-}$currents by injecting either BAPTA or EGTA, and substituted $\mathrm{CaCl}_{2}$ in the ND96 bath solution with $\mathrm{BaCl}_{2}$, which is less likely to activate $\mathrm{Ca}^{2+}$-activated $\mathrm{Cl}^{-}$channels (Barish, 1983). Under these conditions, the inward currents measured were similar to those obtained with $\mathrm{CaCl}_{2}\left(\mathrm{E}_{\mathrm{rev}}=16.2 \pm 0.8 \mathrm{mV}, \mathrm{n}=14\right.$; Figures $1 \mathrm{~B}$ and 1D). Whereas $100 \mu \mathrm{M}$ tetrodotoxin (TTX), a Na 1 blocker, had no effect (Figure S1D), lidocaine inhibited these currents in a dose-dependent manner (Figure 1E), suggesting a structural similarity between $\mathrm{Na}_{v} 2$ and $\mathrm{Na}_{v} 1$ channels at the lidocainebinding site (Cestèle and Catterall, 2000). Moreover, in the presence of $>10 \mathrm{mM}$ lidocaine in the medium, $N$. vectensis adult polyps were paralyzed within $20 \mathrm{~min}$. The lidocaine effects observed in vitro and in vivo suggest that the $\mathrm{Na}_{\mathrm{v}} 2$ channels in $N$. vectensis have a crucial physiological role.

We next examined the $\mathrm{NvNa}_{\mathrm{v}} 2.1$ ion conductance by substituting $\mathrm{Na}^{+}$in the bath solution with impermeable choline ions. Because the reversal potentials with and without $\mathrm{Na}^{+}$in the bath solution were similar $\left(E_{\text {rev }} \mathrm{Na}^{+}=16.2 \pm 0.8 \mathrm{mV}, \mathrm{n}=\right.$ $14 ; E_{\text {rev }}$ choline $=13.3 \pm 0.9 \mathrm{mV}, \mathrm{n}=12$; Figures $1 \mathrm{C}$ and $1 \mathrm{D}$ ), $\mathrm{Ba}^{2+}$ ions were evidently responsible for most of the current measured, implying that under physiological conditions, $\mathrm{Ca}^{2+}$ ions are the main charge carrier conducted by these channels. Using single ion solutions of identical concentrations, we found that the channel was also permeable to $\mathrm{Na}^{+}$and $\mathrm{K}^{+}$ions (permeability ratio $P_{K} / P_{N a}=1$; Figure $2 A$ ).

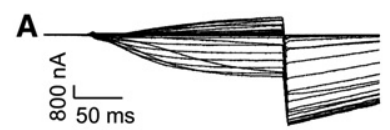

D

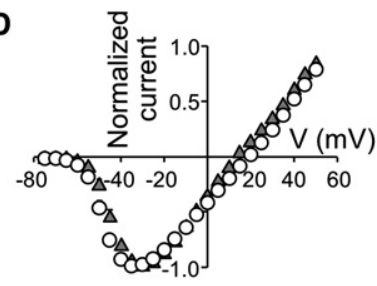

C

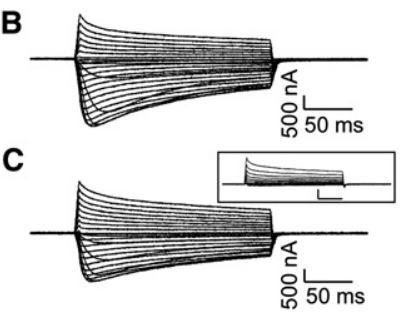

E

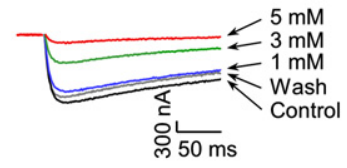

$\mathbf{F}$

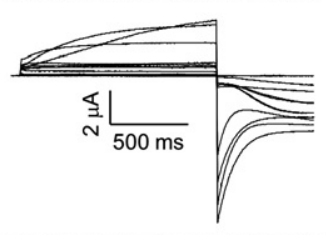

G

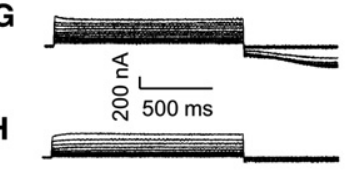

\section{I}
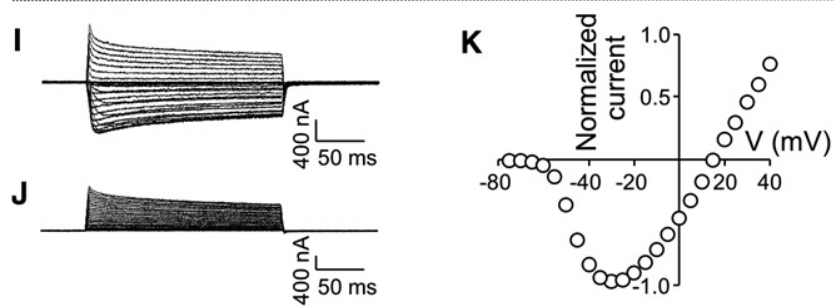

Figure 1. Current Recordings from $\mathrm{NvNa}_{\mathrm{v}} 2.1, \mathrm{NvNa}_{\mathrm{v}} 2.2$, and $\mathrm{NvNa}_{\mathrm{v}} 2.1^{\text {DEKA }}$ Channels Expressed in Xenopus Oocytes

Oocytes were clamped at $-80 \mathrm{mV}$ holding potential, and currents were elicited by $200 \mathrm{~ms}$ depolarizations from $-75 \mathrm{mV}$ to $50 \mathrm{mV}$.

(A) $\mathrm{Ca}^{2+}$-activated $\mathrm{Cl}^{-}$currents recorded in ND96 bath solution from an oocyte expressing $\mathrm{NvNa}_{\mathrm{v}} 2.1$.

(B-E) NvNa 2.1 currents recorded in bath solution with $\mathrm{Ba}^{2+}$ substituting for $\mathrm{Ca}^{2+}$, and in addition with choline substituting for $\mathrm{Na}^{+}(C)$ and also without $\mathrm{Ba}^{2+}$ as control (see inset). See Figure $\mathrm{S} 1$ for further characterization of $\mathrm{NvNa}_{\mathrm{v}} 2.1$. (D) Current-voltage relations of $\mathrm{NvNa}_{\mathrm{v}} 2.1$ (circles: $\mathrm{E}_{\mathrm{rev}}=16.2 \pm 0.8 \mathrm{mV} ; \mathrm{n}=14$ ) and with choline substituting for $\mathrm{Na}^{+}$(triangles: $\mathrm{E}_{\text {rev }}=13.3 \pm 0.9 \mathrm{mV} ; \mathrm{n}=7$ ). (E) Inward currents elicited by $200 \mathrm{~ms}$ depolarizing pulse to $-30 \mathrm{mV}$ in the presence of increasing concentrations of lidocaine. The inhibitory effect of lidocaine was removable by washes with bath solution (gray).

(F) Outward and tail currents elicited by $1 \mathrm{~s}$ depolarizations from $-75 \mathrm{mV}$ to $50 \mathrm{mV}$, measured for an oocyte expressing $\mathrm{NvNa}_{\mathrm{v}} 2.2$ in ND96 bath solution. ( $G$ and $H$ ) Currents decreased in the presence of $5 \mathrm{mM}$ lidocaine $(G)$ and were eliminated when $\mathrm{Ca}^{2+}$ was substituted with $\mathrm{Ba}^{2+}$ ions in the bath solution $(\mathrm{H})$. (I and J) $\mathrm{NvNa}_{\mathrm{v}} 2.1^{\mathrm{DEKA}}$ currents in ND96 bath solution (I) and with choline substituting for $\mathrm{Na}^{+}(\mathrm{J})$.

(K) Current-voltage relations of $\mathrm{NvNa}_{\mathrm{v}} 2.1^{\mathrm{DEKA}}$ in ND96 bath solution $\left(\mathrm{E}_{\text {rev }}=\right.$ $16.7 \pm 1.1 \mathrm{mV} ; n=14)$. Each point represents the mean \pm SEM of $n$ cells.

See also Figure $\mathrm{S} 1$.

In contrast to $\mathrm{NvNa}_{v} 2.1, \mathrm{NvNa}_{\mathrm{v}} 2.2$, bearing a DEET SF, did not exhibit inward currents under various voltage protocols, but lidocaine-sensitive outward and tail currents in ND96 bath solution (with $\mathrm{CaCl}_{2}$ ) were observed (Figures $1 \mathrm{~F}$ and $1 \mathrm{G}$ ). Because no inward currents were detected with $\mathrm{Ba}^{2+}$ substitution for $\mathrm{Ca}^{2+}$ (Figure $1 \mathrm{H}$ ), the tail currents observed were of $\mathrm{Ca}^{2+}$-activated $\mathrm{Cl}^{-}$channels, indicating that $\mathrm{NvNa}_{\mathrm{v}} 2.2$ conducts $\mathrm{Ca}^{2+}$ ions. 
A
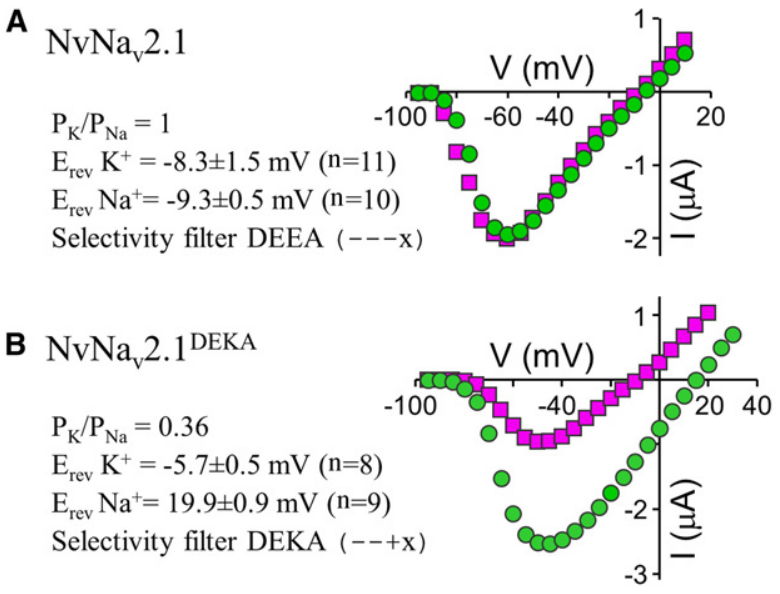

C $\mathrm{NvNa}_{\mathrm{v}} 2.1^{\text {DKEA }}$

$\mathrm{P}_{\mathrm{K}} / \mathrm{P}_{\mathrm{Na}}=0.24$

$\mathrm{E}_{\text {rev }} \mathrm{K}^{+}=-8.7 \pm 0.8 \mathrm{mV}(\mathrm{n}=9)$

$\mathrm{E}_{\text {rev }} \mathrm{Na}^{+}=27.2 \pm 1.6 \mathrm{mV}(\mathrm{n}=9)$

Selectivity filter DKEA $(-+-\mathrm{x})$

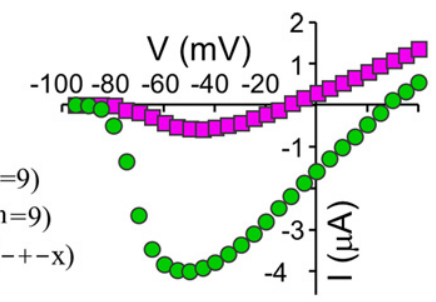

D $\mathrm{NvNa}_{\mathrm{v}} 2.1^{\mathrm{NvNav} 2.5 \text { (p-loops) }}$

$\mathrm{P}_{\mathrm{K}} / \mathrm{P}_{\mathrm{Na}}=0.07$

$\mathrm{E}_{\text {rev }} \mathrm{K}^{+}=-17.8 \pm 1.2 \mathrm{mV}(\mathrm{n}=8)$

$\mathrm{E}_{\text {rev }} \mathrm{Na}^{+}=46.8 \pm 1.4 \mathrm{mV}(\mathrm{n}=7)$

Selectivity filter DKEA $(-+-\mathrm{x})$

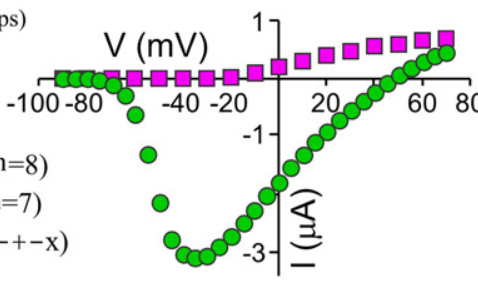

Figure 2. Current-Voltage Relations for $\mathrm{NvNa}_{\mathrm{v}} 2.1$ Mutants in $\mathrm{Na}^{+}$and $\mathrm{K}^{+}$Single lon Solutions and Relative Permeabilities

Currents were elicited for $200 \mathrm{~ms}$ from -95 up to $70 \mathrm{mV}$ from a holding potential of $-100 \mathrm{mV}$.

(A-D) Current-voltage relations of representative oocytes expressing $\mathrm{NvNa}_{\mathrm{v}} 2.1$ (A), $\mathrm{NvNa}_{\mathrm{v}} 2.1^{\mathrm{DEKA}}(\mathrm{B}), \mathrm{NvNa}_{\mathrm{v}} 2.1^{\mathrm{DKEA}}(\mathrm{C})$, or $\mathrm{NvNa}_{\mathrm{v}} 2.1^{\mathrm{NvNav} 2.5(\mathrm{p}-\text { loops) }}$ (D). Circles: $\mathrm{Na}^{+}$single ion solution; squares: $\mathrm{K}^{+}$single ion solution. The relative ion permeability was calculated from the difference in reversal potential between $\mathrm{K}^{+}$and $\mathrm{Na}^{+}$single ion solutions of identical concentrations (see Experimental Procedures). The values provided are the mean \pm SEM of $n$ cells. The protonation state of each SF residue is indicated in parentheses, with $x$ designating an uncharged residue.

See also Figure S2.

We further examined the ion selectivity by introducing the DEKA SF, which is conserved in all $\mathrm{Na}_{v} 1$ channels, in the background of $\mathrm{NvNa}_{\mathrm{v}} 2.1$ (substitution E1239K, mutant $\mathrm{NvNa}_{\mathrm{v}} 2.1^{\mathrm{DEKA}}$ ). No inward current was detectable when $\mathrm{Na}^{+}$ in the bath solution was substituted with choline, indicating that the channel mutant was $\mathrm{Ca}^{2+}$ impermeable $\left(\mathrm{E}_{\mathrm{rev}}=16.7 \pm\right.$ $1.1 \mathrm{mV}, \mathrm{n}=14$; Figures $1 \mathrm{I}-1 \mathrm{~K})$. However, whereas $\mathrm{Na}_{\mathrm{v}} 1$ channels are $\mathrm{Na}^{+}$selective $\left(\mathrm{P}_{\mathrm{K}} / \mathrm{P}_{\mathrm{Na}} \leq 0.1\right.$; Schlief et al., 1996), $\mathrm{NvNa}_{\mathrm{v}} 2.1^{\mathrm{DEKA}}$ conducted both $\mathrm{Na}^{+}$and $\mathrm{K}^{+}$ions $\left(\mathrm{P}_{\mathrm{K}} / \mathrm{P}_{\mathrm{Na}}=\right.$ 0.36 ; Figure $2 \mathrm{~B}$ ). This finding substantiates the structural difference between $\mathrm{Na}_{\mathrm{v}} 1$ and $\mathrm{Na}_{\mathrm{v}} 2$ at the channel pore.
$\mathrm{NvNa}_{\mathrm{v}} 2.5$ Is a $\mathrm{Na}^{+}$-Selective Channel

The unique DKEA SF (Figure $3 \mathrm{~A}$ ) raised questions regarding the ion preference of $\mathrm{NvNa}_{v} 2.5$. Because $\mathrm{NvNa}_{v} 2.5$ did not express in oocytes, we used $\mathrm{NvNa}_{\mathrm{v}} 2.1$ as a platform for analysis of $\mathrm{NvNa}_{\mathrm{v}} 2.5$ ion selectivity. Substitution E800K at DII resulted in mutant $\mathrm{NvNa}_{\mathrm{v}} 2.1^{\mathrm{DKEA}}$, which exhibited biphasic inward currents with a first peak that appeared within milliseconds and a second, slowly developing peak with tail currents (Figure 3B). Substituting $\mathrm{Na}^{+}$with choline or chelating the $\mathrm{Ca}^{+}$in the bath solution with EGTA (Figures $3 \mathrm{C}$ and $3 \mathrm{D}$ ) indicated that the first peak corresponded to $\mathrm{Na}^{+}$currents and the second peak corresponded to $\mathrm{Cl}^{-}$currents induced by $\mathrm{Ca}^{2+}$ conducted by $\mathrm{NvNa}_{\mathrm{v}} 2.1^{\text {DKEA }}$. Furthermore, inward currents were observed in $\mathrm{K}^{+}$single ion solution, indicating that $\mathrm{NvNa}_{\mathrm{v}} 2.1^{\text {DKEA }}$ is nonselective $\left(\mathrm{P}_{\mathrm{K}} / \mathrm{P}_{\mathrm{Na}}=0.24\right.$; Figure $\left.2 \mathrm{C}\right)$. However, in comparison with $\mathrm{NvNa}_{\mathrm{v}} 2.1$, which conducts mainly $\mathrm{Ca}^{2+}$, considerable $\mathrm{Na}^{+}$currents were measured through $\mathrm{NvNa}_{\mathrm{v}} 2.1^{\text {DKEA }}$.

The p-loops of $\mathrm{NvNa}_{\mathrm{v}} 2.5$ differ in sequence from those of the other four $\mathrm{NvNa}_{\mathrm{v}} 2$ channels (Figure $3 \mathrm{~A}$ ). Moreover, transcripts encoding $\mathrm{Na}_{\mathrm{v}} 2.5$ homologs with DKEA SF were previously identified in motor neurons of the hydrozoan Polyorchis penicillatus and the scyphozoan Cyanea capillata, and whole-cell recording in $P$. penicillatus showed $\mathrm{Na}^{+}$-selective voltage-gated ion currents (Anderson et al., 1993; Spafford et al., 1996). Therefore, we constructed the $\mathrm{NvNa}_{\mathrm{v}} 2.5 \mathrm{p}$-loops of all four domains in the background of $\mathrm{NvNa}_{v} 2.1$ and examined the ion selec-

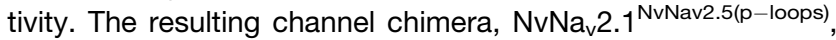
was $\mathrm{Ca}^{2+}$ impermeable (Figures $3 \mathrm{E}$ and $3 \mathrm{~F}$ ), with an $\mathrm{E}_{\text {rev }}$ value of $46.5 \pm 1.2 \mathrm{mV}(n=19$; Figure $3 G)$ and $P_{K} / P_{N a}$ ratio of 0.07 (Figure 2D) resembling those of $\mathrm{Na}_{v} 1$ channels (insect channel $\mathrm{DmNa}_{\mathrm{v}} 1 \mathrm{E}_{\mathrm{rev}}=47.8 \pm 1.1 \mathrm{mV}, \mathrm{n}=17$; mammalian brain channel $\mathrm{rNa}_{\mathrm{v}} 1.2 \mathrm{E}_{\mathrm{rev}}=48.9 \pm 2.3 \mathrm{mV}, \mathrm{n}=14$; data not shown). These characteristics suggest that $\mathrm{NvNa}_{\mathrm{v}} 2.1^{\mathrm{NvNav} 2.5(\mathrm{p}-\mathrm{loops})}$ is $\mathrm{Na}^{+}$selective. Of note, the $\mathrm{Na}^{+}$selectivity was lost when the DKEA SF was substituted with DEEA or DEKA (Figure S2).

Based on mutagenesis of the $\mathrm{Na}_{\mathrm{v}} 1$ DEKA SF, DKEA in the $\mathrm{Na}_{\mathrm{v}} 2.5$ channel was considered an intermediate between DEKA and DEEA SFs (Schlief et al., 1996; Liebeskind et al., 2011). However, here we show not only that $\mathrm{NvNa}_{\mathrm{v}} 2.5$ is as $\mathrm{Na}^{+}$selective as $\mathrm{Na}_{v} 1$, but also that this selectivity cannot be conferred by the DKEA SF alone. Because $\mathrm{Na}^{+}$selectivity in $\mathrm{NvNa}_{\mathrm{v}} 2.1$ was achieved only when the entire p-loop region was exchanged by that of $\mathrm{NvNa}_{v} 2.5$, other residues in addition to those of the SF are involved in determining the $\mathrm{Na}^{+}$selectivity of $\mathrm{NvNa}_{\mathrm{v}} 2.5$.

The multiple $\mathrm{Na}_{\mathrm{v}} 2$ genes in $\mathrm{N}$. vectensis suggested variable spatiotemporal expression, and indeed this was demonstrated by quantitative PCR (qPCR) analysis and distinct in situ hybridization expression patterns (Figure S3). Using two Clytia hemisphaerica sodium channel cDNA clones homologous to $\mathrm{NvNa}_{v} 2.1$ and $\mathrm{NvNa}_{\mathrm{v}} 2.5\left(\mathrm{ChNa}_{\mathrm{v}} 2.1\right.$ and $\left.\mathrm{ChNa}_{\mathrm{v}} 2.5\right)$, and in situ hybridization, we observed differential channel expression in two distinct developmental stages of this hydrozoan (Figures S3G-S3J). Thus, similarly to bilaterian animals, cnidarians possess several channel subtypes distributed in a spatiotemporal manner, possibly reflecting specialized physiological 
A DI

NvNa $_{\mathrm{v}} 2.1$ QLVTMDFWENVYNY

NvNa $_{v} 2.2$ QILTMDFWENLYDR

$\mathrm{NVNa}_{\mathrm{v}} 2.3$ QLLTLDFWENLYNK

NvNa, 2.4 OLITLDFWENVYNN

$\mathrm{NVNa}_{\mathrm{v}} 2.5$ QLVTMDY्YESIYNS

CCNa,2.5 QVCTLDYWESVYNS

$\mathrm{PpNa}_{\mathrm{v}} 2.5$ QVCTLDYWESVFNS

$\mathrm{Na}_{\mathrm{v}} 1.2$ RLMTQDFWENLYQI

DIII

$\mathrm{NVNa}_{\mathrm{v}} 2.1$ QVATFEGWIEIMRD $\mathrm{NVNa}_{\mathrm{v}} 2.2$ QVATYEGWMEVMAD $\mathrm{NVNa}_{\mathrm{v}} 2.3$ QVATFEGWMEVMGD NvNa 2.4 OVATEEGWME IMED $\mathrm{NVNa}_{\mathrm{v}} 2.5$ QVATLEGVEEVMND $\mathrm{CCNa}_{\mathrm{v}} 2.5$ QTATLEGWFEVMQD $\mathrm{PpNa}_{\mathrm{v}} 2.5$ QTATLEGWFEAMAD $\mathrm{Na}_{\mathrm{v}} 1.2$ QVATFKGWMDIMYA

B

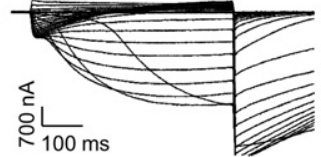

C

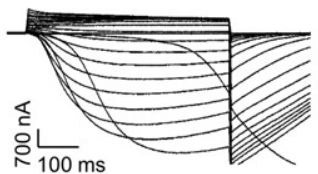

D

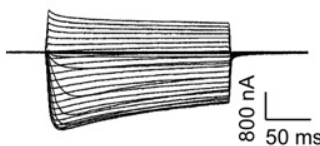

DII

NVNa 2.1 RVLCGEWIEPLHDC NVNa 2.2 RILCSEWVEPLWDC $\mathrm{NVNa}_{\mathrm{v}} 2.3$ RILCGEWIEPLWDC NVNa,2.4 RVLCGEWIEPLWDC $\mathrm{NVNa}_{\mathrm{v}} 2.5$ RILCGKWIEPLWAT $\mathrm{CCNa}_{\mathrm{v}} 2.5$ RILCGKWIEPOWDI $\mathrm{PpNa}_{\mathrm{v}} 2.5$ RILCGKWIEPQWDI $\mathrm{Na}_{v} 1.2$ RVLCGEWIETMWDC

DIV

$\mathrm{NVNa}_{\mathrm{v}} 2.1$ RLSTSAGWNDVLNP NvNa 2.2 RLGTGTGWNDILDA $\mathrm{NVNa}_{\mathrm{v}} 2.3$ RLSTGAGWNDILDS $\mathrm{NVNa}_{\mathrm{v}} 2.4$ RLMTSAGWNDVLN $\mathrm{NvNa}_{\mathrm{v}} 2.5$ RIGTAAGWNTILD $\mathrm{CCNa}_{\mathrm{v}} 2.5$ RISTAAGWNGVLEA PpNa 2.5 RISTAAGWNGVLDA $\mathrm{Na}_{\mathrm{v}} 1.2$ QITTSAGWDGLLAP

E

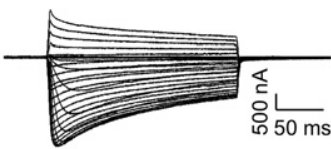

F

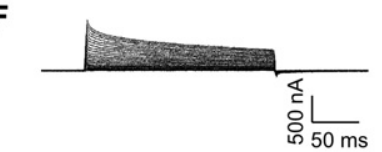

G

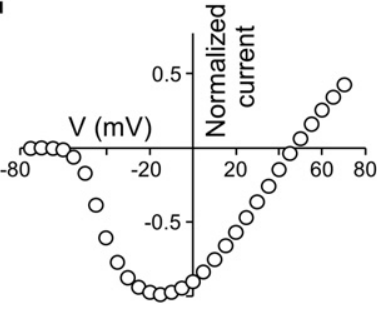

Figure 3. Sequence Alignment of $\mathrm{NvNa}_{\mathrm{v}} 2$ Channels and Current

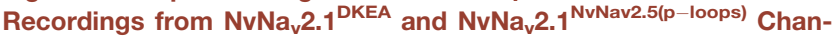
nels Expressed in Xenopus Oocytes

(A) Alignment of the pore-loop regions of the five N. vectensis (Nv) channels (see also Figure $\mathrm{S} 3$ for spatiotemporal expression of $\mathrm{Na}_{\mathrm{v}} 2$ cnidarian channels), as well as a channel from the medusae $P$. penicillatus $(\mathrm{Pp})$ and $C$. capillata $(\mathrm{Cc})$ and the mammalian brain channel $\mathrm{Na}_{v} 1.2$. Substitutions of $\mathrm{NvNa}_{\mathrm{v}} 2.1^{\mathrm{NvNav} 2.5(\mathrm{p}-\mathrm{loops})}$ are underlined and substitutions unique to the $\mathrm{Na}_{\mathrm{v}} 2.5$ channel subfamily are in yellow boxes. For current recordings the oocytes were clamped at $-80 \mathrm{mV}$ holding potential and currents were elicited by 200 or $500 \mathrm{~ms}$ depolarizing voltage pulses from $-75 \mathrm{mV}$ to either 50 or $70 \mathrm{mV}$

(B) $\mathrm{NvNa}_{v} 2.1^{\text {DKEA }}$ in ND96 bath solution.

(C) $\mathrm{NvNa}_{v} 2.1^{\mathrm{DKEA}}$ with choline substituting for $\mathrm{Na}^{+}$in the bath solution.

(D) $\mathrm{NvNa}_{\mathrm{v}} 2.1^{\text {DKEA }}$ with $\mathrm{Ca}^{2+}$ in the bath solution chelated by EGTA

( $E$ and $F) \mathrm{NvNa}_{\mathrm{v}} 2.1^{\mathrm{NvNav} 2.5(\mathrm{p}-\mathrm{loops})}$ in ND96 bath solution $(\mathrm{E})$ and with choline substituting for $\mathrm{Na}^{+}(\mathrm{F})$.

(G) Current-voltage relations of $\mathrm{NvNa}_{v} 2.1^{\mathrm{NvNav2.5(p-loops})}\left(\mathrm{E}_{\text {rev }}=46.5 \pm 1.2 \mathrm{mV}\right.$; $n=19$ ). Each point represents mean \pm SEM of $n$ cells (see Figure $S 2$ for analysis of the SF in $\left.\mathrm{NvNa}_{\mathrm{v}} 2.1^{\mathrm{NvNav} 2.5(\mathrm{p}-\mathrm{loops})}\right)$.

roles. Given the complex expression of other neuronal genes in $N$. vectensis (Marlow et al., 2009) and the correlation between the increase in the number of $\mathrm{Na}_{\mathrm{v}}$ genes and neuronal complexity in bilaterians (Widmark et al., 2011), cnidarian excitability is probably more complex than was initially hypothesized.

\section{$\mathrm{Na}^{+}$-Channel Phylogeny Reveals Convergent Evolution} of Sodium Selectivity

The characterization of sea anemone $\mathrm{Na}_{\mathrm{v}} 2$ channels, especially the $\mathrm{Na}^{+}$-selective $\mathrm{NvNa}_{\mathrm{v}} 2.5$, prompted us to reanalyze the evolutionary history of sodium channels. We extended the data set of $\mathrm{Na}_{\mathrm{v}}$ sequences with full-length cDNAs encoding $\mathrm{Na}_{\mathrm{v}} 2$ homologs, which we cloned from basal metazoans and their relatives (Figure 4 and Table S1). We also identified and cloned $\mathrm{Na}_{\mathrm{v}} 2.1$ and $\mathrm{Na}_{\mathrm{v}} 2.5$ homologs from the hydroid cnidarians Hydra magnipapillata (Chapman et al., 2010) and Clytia hemisphaerica (J.E.M.K., unpublished data). Our phylogenetic analysis with the extended data set using the putative channel of the diatom Thalassiosira pseudonana as an outgroup (Derelle and Lang, 2012) positioned the $\mathrm{Na}_{\mathrm{v}} 2$ channels within a single cluster containing all metazoan $\mathrm{Na}_{\mathrm{v}} \mathrm{s}$ and a putative homolog from $T$. trahens (Figure 4). This phylogeny confirms that $\mathrm{Na}_{\mathrm{v}} 2$ channels appeared prior to the metazoan-fungal split (Cai, 2012), and that they were retained in most extant nonbilaterian animals but not in fungi or the unicellular opisthokont Capsaspora owczarzaki. $\mathrm{Na}_{\mathrm{v}} 2$ channels are also found in many bilaterians, but were lost in vertebrates. $\mathrm{Na}_{\mathrm{v}} 1$ channels, however, are found only in bilaterians (Figure 4; Liebeskind et al., 2011). Although $\mathrm{Na}_{\mathrm{v}} 2$ channels mediate $\mathrm{Ca}^{2+}$, they cluster with $\mathrm{Na}_{v} 1$ channels rather than $\mathrm{Ca}_{\mathrm{v}} \mathrm{s}$. Because $\mathrm{Na}_{\mathrm{v}} 2$ channels coexisted with $\mathrm{Ca}_{\mathrm{v}} \mathrm{s}$ in the ancestor of T. trahens and opisthokonts (Cai, 2012), the separation of $\mathrm{Na}_{\mathrm{v}} \mathrm{s}$ from $\mathrm{Ca}_{\mathrm{v}} \mathrm{s}$ occurred more than a billion years ago.

The $N$. vectensis channels $\left(\mathrm{NvNa}_{\mathrm{v}} 2.1-\mathrm{NvNa}_{\mathrm{v}} 2.5\right)$ are clustered with channels of other cnidarians, indicating a monophyletic origin (Figure 4). $\mathrm{NvNa}_{\mathrm{v}} 2.5$, however, forms a small subcluster together with hydrozoan and scyphozoan $\mathrm{Na}_{\mathrm{v}} \mathrm{s}$ bearing a unique DKEA SF, suggesting that the $\mathrm{Na}_{\mathrm{v}} 2.1$ and $\mathrm{Na}_{\mathrm{v}} 2.5$ subtypes resulted from a gene duplication event in the common ancestor of all extant cnidarians $>540$ million years ago (Park et al., 2012). The selective $\mathrm{Na}^{+}$conductance of the $\mathrm{Na}_{\mathrm{v}} 2.5$ subfamily explains the sodium-based action potentials measured in isolated motor neurons of the medusozoans Cyanea and Polyorchis (Anderson, 1987; Spafford et al., 1996).

Our results indicate that selectivity for $\mathrm{Na}^{+}$evolved separately in the cnidarian and bilaterian lineages. Moreover, a single substitution at the third position in the SF of $\mathrm{NvNa}_{2} 2.1$, to resemble the DEKA SF of $\mathrm{Na}_{v} 1$ channels $\left(\mathrm{NvNa}_{\mathrm{v}} 2.1^{\mathrm{DEKA}}\right)$, abolished $\mathrm{Ca}^{2+}$ but not $\mathrm{K}^{+}$conductance. Because $\mathrm{K}^{+}$ion conductance through $\mathrm{K}_{\mathrm{v}} \mathrm{s}$ generates the falling phase of the action potential, whereas $\mathrm{Na}^{+}$ion conductance through $\mathrm{Na}_{\mathrm{v}} \mathrm{s}$ is responsible for its rising phase, a clear functional advantage would be gained by separating these two fluxes and increasing the selectivity of $\mathrm{Na}_{\mathrm{v}} 2$ channels to $\mathrm{Na}^{+}$ions. We therefore propose that the pore regions in both the urbilaterian $\mathrm{Na}_{v} 1$ and the primordial $\mathrm{Na}_{\mathrm{v}} 2.5$ cnidarian channel evolved under selective pressure to cease $\mathrm{K}^{+}$and $\mathrm{Ca}^{2+}$ ion conductance, and that this required additional substitutions at the $\mathrm{p}$-loops other than those at the SF. The selectivity for $\mathrm{Na}^{+}$was achieved in the two channel types in different ways, as is evident from the lack of selectivity for $\mathrm{Na}^{+}$ ions in channel mutants $\mathrm{NvNa}_{\mathrm{v}} 2.1^{\mathrm{NvNav2.5}(\mathrm{p} \text {-loops } \mathrm{DEKA})}$ bearing the SF of $\mathrm{Na}_{\mathrm{v}} 1$, and $\mathrm{Na}_{\mathrm{v}} 1.2^{\text {DKEA }}$ (a mammalian brain channel mutant) bearing the SF of $\mathrm{NvNa}_{\mathrm{v}} 2.5$ (Figure S2; Schlief et al., 1996). This conclusion argues for a structural difference between the pore regions of $\mathrm{Na}_{v} 2.5$ and $\mathrm{Na}_{v} 1$, which is conceivable given 


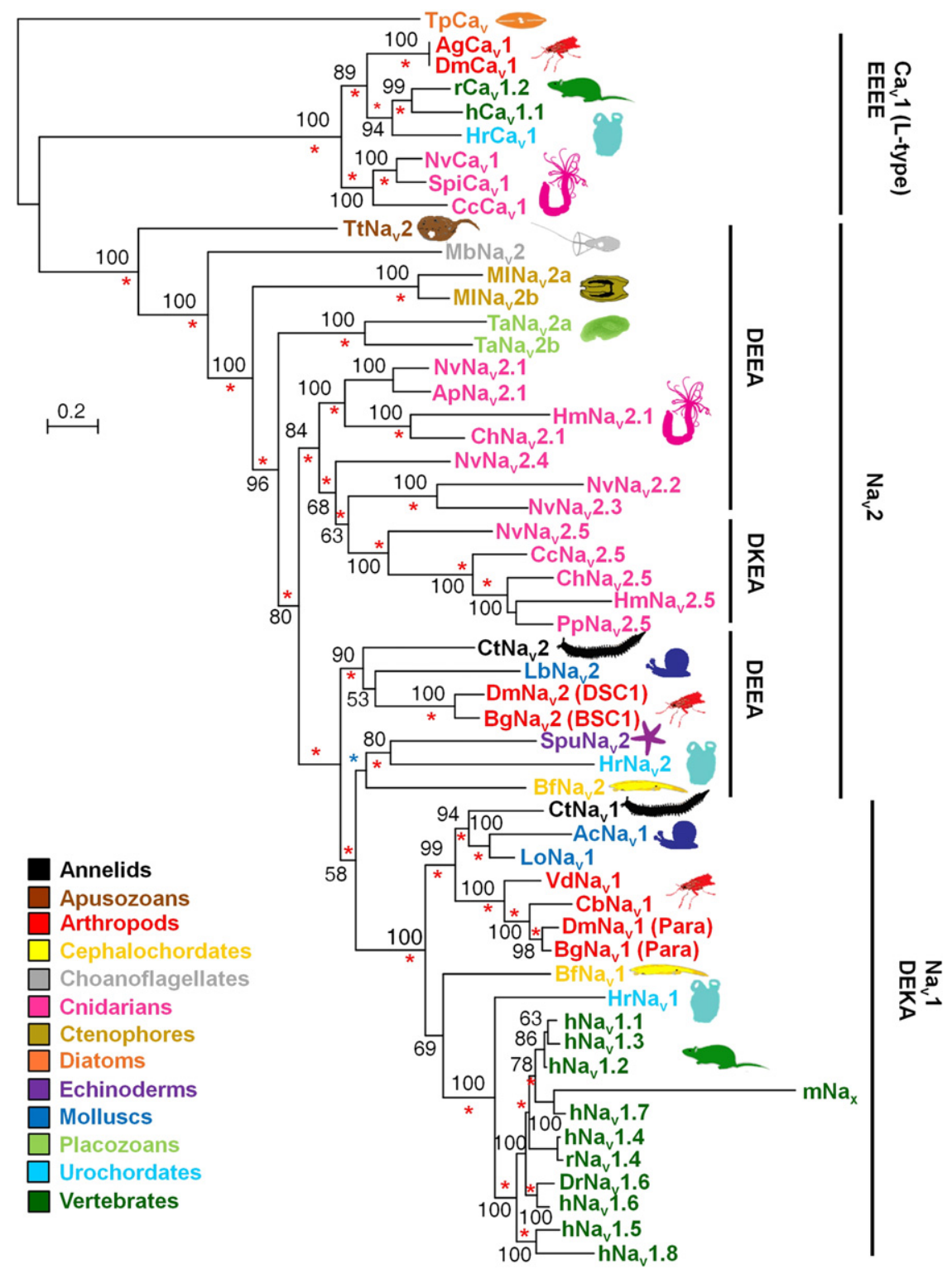

that $\mathrm{Na}^{+}$selectivity in cnidarian $\mathrm{Na}_{\mathrm{v}} 2.5$ channels and bilaterian $\mathrm{Na}_{\mathrm{v}} 1$ channels has evolved in a convergent manner.

Bacterial homotetrameric $\mathrm{Na}_{v} \mathrm{~s}$ bear an EEEE SF similar to that of metazoan $\mathrm{Ca}_{\mathrm{v}} \mathrm{s}$, but they are still selective for $\mathrm{Na}^{+}$ions (Payandeh et al., 2011). Thus, $\mathrm{Na}^{+}$selectivity in voltage-gated ion channels evolved independently in three lineages on the tree of life. This highlights the plasticity of molecular evolution and the importance of $\mathrm{Na}^{+}$selectivity in biological systems ranging from prokaryotes to advanced eukaryotes.

Intriguingly, despite the advantages of $\mathrm{Na}^{+}$selectivity, several animal lineages with simple nervous systems (e.g., nematodes and echinoderms) appear to have independently lost the $\mathrm{Na}_{\mathrm{v}} 1$ channels (Figure 4; Widmark et al., 2011; Jegla et al., 2009). Moreover, $\mathrm{Na}_{\mathrm{v}} 2$ channels with a $\mathrm{Ca}^{2+}$ preference were retained in parallel to $\mathrm{Na}^{+}$selective channels in many animal groups, such as ascidians, insects, and cnidarians (Figure 4; Nagahora
Figure 4. Phylogeny of Voltage-Gated Sodium Channels

A maximum-likelihood tree was constructed using the $L G(+F+G+I)$ model. The bootstrap support out of 100 is indicated at the branches. A Bayesian analysis using the WAG model resulted in identical topology. Posterior probabilities of 1.0 are indicated by a red asterisk, and those of $0.95<\mathrm{X}<1.0$ are indicated by a blue asterisk. All sequences are from cloned cDNA unless otherwise mentioned. Accession numbers and species names are available in Table S1. Animal clades are indicated by colors.

et al., 2000; Cui et al., 2012). Thus, it seems that $\mathrm{Ca}^{2+}$-based action potentials are not merely an evolutionary relic but may be advantageous in simple neuronal circuits.

\section{EXPERIMENTAL PROCEDURES}

Identification of $\mathrm{Na}_{\mathrm{v}}$ Homologs

Putative $\mathrm{Na}_{\mathrm{v}}$ homologs were detected in GenBank (nr), Broad Institute, and Joint Genome Institute databases via BLAST. The voltage sensors, SF, and inactivation loop were assigned manually. Because some of these regions were missing or contained noncanonical substitutions, we cloned and sequenced overlapping cDNA fragments encoding the putative $\mathrm{Na}_{\mathrm{v}} \mathrm{s}$ from several basal metazoans and a choanoflagellate (see Table S1).

Functional Expression of $\mathrm{Na}_{\mathrm{v}} \mathrm{s}$ in Oocytes and Two-Electrode Voltage Clamp Measurements

$\mathrm{Na}_{\mathrm{v}}$-like transcripts were cloned into a modified pAlter expression vector (Promega). Constructs encoding the $\mathrm{Na}_{v} \alpha$-subunits were linearized, transcribed in vitro, and injected into Xenopus oocytes as described previously (Shichor et al., 2002). Currents were measured 1-3 days later using a two-electrode voltage clamp and a Gene Clamp 500 amplifier (Axon Instruments). Data were sampled at $10 \mathrm{kHz}$ and filtered at $5 \mathrm{kHz}$. Unless otherwise stated, the ND96 bath solution contained (in $\mathrm{mM}$ ) $96 \mathrm{NaCl}, 2 \mathrm{KCl}$, $1 \mathrm{MgCl}_{2}, 1.8 \mathrm{CaCl}_{2}, 5 \mathrm{HEPES}, \mathrm{pH}$ 7.5. For G-V analysis, the mean conductance $(G)$ was calculated from the peak current-voltage relations using the equation $G=I /\left(V-E_{r e v}\right)$, where $I$ is the peak current, $V$ is the membrane potential, and $E_{r e v}$ is the reversal potential. The normalized conductance-voltage relations were fit with either a one- or two-component Boltzmann distribution according to the equation:

$$
\frac{G}{G_{\max }}=\frac{(1-A)}{\left(1+\exp \left[\left(\mathrm{V} 1_{1 / 2}-\mathrm{V}\right) / k_{1}\right]\right)}+\frac{A}{\left(1+\exp \left[\left(\mathrm{V} 2_{1 / 2}-\mathrm{V}\right) / k_{2}\right]\right)},
$$

where $\mathrm{V} 1_{1 / 2}$ and $\mathrm{V} 2_{1 / 2}$ are the respective membrane potentials for two populations of channels for which the mean conductance is half maximal, $k_{1}$ and $k_{2}$ are their respective slopes, and $A$ defines the proportion of the second population (amplitude) over the total. When only one population of channels was apparent, $A$ was set to zero. To avoid the $\mathrm{Ca}^{2+}$-activated chloride currents in oocytes expressing $\mathrm{NvNa}_{\mathrm{v}} 2.1, \mathrm{CaCl}_{2}$ in the $\mathrm{ND} 96$ bath solution was substituted with $\mathrm{BaCl}_{2}$, and the oocytes were injected $30 \mathrm{~min}$ or $2 \mathrm{hr}$ prior to 
the measurements with $25 \mathrm{~nL}$ of either $50 \mathrm{mM}$ BAPTA or EGTA, respectively. The relative ion permeability $\mathrm{P}_{K} / \mathrm{P}_{\mathrm{Na}}$ was determined by measuring the difference in reversal potential between the test solution $\left(\mathrm{K}^{+}\right.$single ion solution) and the reference solution $\left(\mathrm{Na}^{+}\right.$single ion solution; see Extended Experimental Procedures). In the case of equal concentrations, the following equation was used (Hille, 2001):

$$
\Delta \mathrm{E}_{\mathrm{rev}}=\mathrm{E}_{\mathrm{rev}}(X)-\mathrm{E}_{\mathrm{rev}}(\mathrm{Na})=\frac{R T}{F} \ln \left(\frac{\mathrm{P}_{\mathrm{X}}}{\mathrm{P}_{\mathrm{Na}}}\right),
$$

where $\mathrm{R}, \mathrm{T}$, and $\mathrm{F}$ are the gas constant, absolute temperature, and Faraday's constant, respectively.

\section{Characterization of Spatiotemporal Expression Patterns}

The main parameters of the qPCR analysis followed an established protocol (Reitzel and Tarrant, 2009; see Extended Experimental Procedures). In situ hybridization in $N$. vectensis was carried out according to an established method (Genikhovich and Technau, 2009). C. hemisphaerica young medusae and gastrozoids were fixed in $3.7 \%$ formaldehyde and $0.2 \%$ glutaraldehyde in seawater for $1 \mathrm{hr}$ at $4^{\circ} \mathrm{C}$. In situ hybridization in Clytia was performed according to the $N$. vectensis protocol, but specimens were digested in a higher concentration of Proteinase $\mathrm{K}(0.02 \mathrm{mg} / \mathrm{ml})$ to improve permeability.

\section{Phylogenetic Analysis}

Channel protein sequences were aligned with the use of MUSCLE (Edgar, 2004), and low-quality alignment regions were removed by the TrimAl program (Capella-Gutiérrez et al., 2009). ProtTest was used to determine the most suitable model for phylogenetic reconstruction of $\mathrm{Na}_{\mathrm{v}} \mathrm{s}$ (Abascal et al., 2005). A maximum-likelihood phylogenetic tree was constructed using PhyML with the LG Model (+I +G +F; Guindon et al., 2010). Support values were calculated using 100 bootstrap replicates. Bayesian phylogenetic reconstruction was carried out using MrBayes 3.1 and the WAG model. A total of 5,000,000 generations were calculated and every 100th generation was sampled.

\section{ACCESSION NUMBERS}

All novel sequences have been deposited in GenBank under accession numbers HQ877452-HQ877461 and JQ066819-JQ066822.

\section{SUPPLEMENTAL INFORMATION}

Supplemental Information includes Extended Experimental Procedures, three figures, and one table and can be found with this article online at http://dx.doi. org/10.1016/j.celrep.2012.06.016.

\section{LICENSING INFORMATION}

This is an open-access article distributed under the terms of the Creative Commons Attribution-Noncommercial-No Derivative Works 3.0 Unported License (CC-BY-NC-ND; http://creativecommons.org/licenses/by-nc-nd/3.0/ legalcode).

\section{ACKNOWLEDGMENTS}

We thank N. King and M.J. Westbrook (University of California, Berkeley), L.Z. Holland (University of California, San Diego), P.A.V. Anderson (University of Florida), and B. Schierwater and M. Eitel (Institut für Tierökologie und Zellbiologie, Hannover) for providing RNA and tissue samples; D. Fredman (University of Vienna) for sharing data; and T.J. Jegla (Penn State University) and N. Dascal (Tel Aviv University) for critical comments. Y.M. was supported by an EMBO long-term fellowship (ALTF 1096-2009). A.M.R. was supported by award F32HD062178 from the Eunice Kennedy Shriver National Institute of Child Health and Human Development. This study was supported by a research grant from the Austrian National Science Foundation (FWF P 21108-B17) to U.T., and by a United States-Israel Binational Agricultural
Research and Development Grant (IS-4313-10) and an Israeli Science Foundation grant $(107 / 08)$ to M.G.

Received: February 20, 2012

Revised: May 14, 2012

Accepted: June 21, 2012

Published online: July 26, 2012

\section{REFERENCES}

Abascal, F., Zardoya, R., and Posada, D. (2005). ProtTest: selection of best-fit models of protein evolution. Bioinformatics 21, 2104-2105.

Anderson, P. (1987). Properties and pharmacology of a TTX insensitive $\mathrm{Na}^{+}$ current in neurones of the jellyfish Cyanea Capillata. J. Exp. Biol. 133, 231-248.

Anderson, P.A., Holman, M.A., and Greenberg, R.M. (1993). Deduced amino acid sequence of a putative sodium channel from the scyphozoan jellyfish Cyanea capillata. Proc. Natl. Acad. Sci. USA 90, 7419-7423.

Barish, M.E. (1983). A transient calcium-dependent chloride current in the immature Xenopus oocyte. J. Physiol. 342, 309-325.

Cai, X. (2012). Ancient origin of four-domain voltage-gated $\mathrm{Na}^{+}$channels predates the divergence of animals and fungi. J. Membr. Biol. 245, 117-123.

Capella-Gutiérrez, S., Silla-Martínez, J.M., and Gabaldón, T. (2009). trimAl: a tool for automated alignment trimming in large-scale phylogenetic analyses. Bioinformatics 25, 1972-1973.

Catterall, W.A. (2000). From ionic currents to molecular mechanisms: the structure and function of voltage-gated sodium channels. Neuron 26, 13-25.

Cestèle, S., and Catterall, W.A. (2000). Molecular mechanisms of neurotoxin action on voltage-gated sodium channels. Biochimie 82, 883-892.

Chapman, J.A., Kirkness, E.F., Simakov, O., Hampson, S.E., Mitros, T., Weinmaier, T., Rattei, T., Balasubramanian, P.G., Borman, J., Busam, D., et al. (2010). The dynamic genome of Hydra. Nature 464, 592-596.

Cui, Y.J., Yu, L.L., Xu, H.J., Dong, K., and Zhang, C.X. (2012). Molecular characterization of DSC1 orthologs in invertebrate species. Insect Biochem. Mol. Biol. 42, 353-359.

Derelle, R., and Lang, B.F. (2012). Rooting the eukaryotic tree with mitochondrial and bacterial proteins. Mol. Biol. Evol. 29, 1277-1289.

Edgar, R.C. (2004). MUSCLE: a multiple sequence alignment method with reduced time and space complexity. BMC Bioinformatics 5, 113.

Genikhovich, G., and Technau, U. (2009). In situ hybridization of starlet sea anemone (Nematostella vectensis) embryos, larvae, and polyps. Cold Spring Harb. Protoc. 2009(9), pdb.prot5282.

Goldin, A.L. (2002). Evolution of voltage-gated $\mathrm{Na}\left({ }^{+}\right)$channels. J. Exp. Biol. 205, 575-584.

Guindon, S., Dufayard, J.F., Lefort, V., Anisimova, M., Hordijk, W., and Gascuel, O. (2010). New algorithms and methods to estimate maximum-likelihood phylogenies: assessing the performance of PhyML 3.0. Syst. Biol. 59, 307-321.

Heinemann, S.H., Terlau, H., Stühmer, W., Imoto, K., and Numa, S. (1992). Calcium channel characteristics conferred on the sodium channel by single mutations. Nature 356, 441-443.

Hille, B. (2001). Ion Channels of Excitable Membranes, Third Edition (Sunderland, MA: Sinauer Associates Inc.).

Jegla, T.J., Zmasek, C.M., Batalov, S., and Nayak, S.K. (2009). Evolution of the human ion channel set. Comb. Chem. High Throughput Screen. 12, 2-23.

Liebeskind, B.J., Hillis, D.M., and Zakon, H.H. (2011). Evolution of sodium channels predates the origin of nervous systems in animals. Proc. Natl. Acad. Sci. USA 108, 9154-9159.

Marlow, H.Q., Srivastava, M., Matus, D.Q., Rokhsar, D., and Martindale, M.Q. (2009). Anatomy and development of the nervous system of Nematostella vectensis, an anthozoan cnidarian. Dev. Neurobiol. 69, 235-254. 
Meech, R.W., and Mackie, G.O. (2007). Evolution of excitability in lower metazoans, G. North and J. Greenspann, eds. (New York: Cold Spring Harbor Laboratory Press), pp. 581-615.

Nagahora, H., Okada, T., Yahagi, N., Chong, J.A., Mandel, G., and Okamura, Y. (2000). Diversity of voltage-gated sodium channels in the ascidian larval nervous system. Biochem. Biophys. Res. Commun. 275, 558-564.

Park, E., Hwang, D.S., Lee, J.S., Song, J.I., Seo, T.K., and Won, Y.J. (2012). Estimation of divergence times in cnidarian evolution based on mitochondrial protein-coding genes and the fossil record. Mol. Phylogenet. Evol. 62, 329-345.

Payandeh, J., Scheuer, T., Zheng, N., and Catterall, W.A. (2011). The crystal structure of a voltage-gated sodium channel. Nature 475, 353-358.

Putnam, N.H., Srivastava, M., Hellsten, U., Dirks, B., Chapman, J., Salamov, A., Terry, A., Shapiro, H., Lindquist, E., Kapitonov, V.V., et al. (2007). Sea anemone genome reveals ancestral eumetazoan gene repertoire and genomic organization. Science 317, 86-94.

Reitzel, A.M., and Tarrant, A.M. (2009). Nuclear receptor complement of the cnidarian Nematostella vectensis: phylogenetic relationships and developmental expression patterns. BMC Evol. Biol. 9, 230.

Sato, C., and Matsumoto, G. (1992). Primary structure of squid sodium channel deduced from the complementary DNA sequence. Biochem. Biophys. Res. Commun. 186, 61-68.
Schlief, T., Schönherr, R., Imoto, K., and Heinemann, S.H. (1996). Pore properties of rat brain II sodium channels mutated in the selectivity filter domain. Eur. Biophys. J. 25, 75-91.

Shichor, I., Zlotkin, E., Ilan, N., Chikashvili, D., Stuhmer, W., Gordon, D., and Lotan, I. (2002). Domain 2 of Drosophila para voltage-gated sodium channe confers insect properties to a rat brain channel. J. Neurosci. 22, 4364-4371.

Spafford, J., Grigoriev, N., and Spencer, A. (1996). Pharmacological properties of voltage-gated $\mathrm{Na}^{+}$currents in motor neurones from a hydrozoan jellyfish Polyorchis penicillatus. J. Exp. Biol. 199, 941-948.

Watanabe, H., Fujisawa, T., and Holstein, T.W. (2009). Cnidarians and the evolutionary origin of the nervous system. Dev. Growth Differ. 51, 167-183.

Widmark, J., Sundström, G., Ocampo Daza, D., and Larhammar, D. (2011) Differential evolution of voltage-gated sodium channels in tetrapods and teleost fishes. Mol. Biol. Evol. 28, 859-871.

Zhang, T., Liu, Z., Song, W., Du, Y., and Dong, K. (2011). Molecular characterization and functional expression of the DSC1 channel. Insect Biochem. Mol. Biol. 41, 451-458.

Zhou, W., Chung, I., Liu, Z., Goldin, A.L., and Dong, K. (2004). A voltage-gated calcium-selective channel encoded by a sodium channel-like gene. Neuron $42,101-112$. 